\title{
Selected Abstracts From the 2010 Annual Scientific Meeting
}

\section{The Utilization of Chemical "Hard Warmers" and Multiple Insulation Methods for Warming of Normal Saline in Cold Environment}

Background.--It has been reported that chemical "hand warmers" can be utilized to warm intravenous (IV) normal saline (NS) for use in rewarming of hypothermic patients. The suggested fluid temperatures range from $37^{\circ} \mathrm{C}$ to $41^{\circ} \mathrm{C}$.

Objectives.-The objectives of this prospective, interventional study are to determine the maximum temperature achieved, time to maximum temperature, and efficacy of insulation in warming NS.

Methods.-The study was performed in February 2010 in downstate New York. Twelve 1-L IV NS bags were cooled to $3^{\circ} \mathrm{C}$ and divided into 4 warming groups: (1) wrapped with 8 Grabbers (Grand Rapids, MI) 7-hour hand warmers secured by duct tape; (2) wrapped with 3 Grabbers Peel N' Stick Adhesive body warmers; (3) duct tape/8 hand warmers with foil blanket insulation; (4) duct tape/8 hand warmers with Ensolite type foam insulation. The Grabbers company reported an average warmer temperature of $57^{\circ} \mathrm{C}$. Temperature measurements were taken every 5 minutes with a digital metal probe (Vernier. Beaverton, OR) from each IV bag. The mean temperatures of the 4 groups at 5-minute intervals were used for Mann-Whitney $\mathrm{U}$ analysis.

Results.-The study environment temperature was $0^{\circ} \mathrm{C}$. The hand warmer/tape group plateaued at 135 minutes with $12.43^{\circ} \mathrm{C}$. The adhesive warmer group plateaued at 145 minutes with $13.8^{\circ} \mathrm{C}$. The foil insulation group plateaued at 145 minutes with $14.33^{\circ} \mathrm{C}$. The Ensolite group plateaued at 145 minutes with $17.63^{\circ} \mathrm{C}$. The temperature difference between the warmer/duct tape, adhesive, and foil insulation group did not achieve significance. The temperature difference between the warmer/duct tape and the foam insulation group was significant, $p<0.00019$.

Conclusions.-Hand warmers failed to quickly or adequately warm IV NS to usable temperature for hypothermia treatment. Use of foam insulation improves heat transfer to the IV NS. Limitations included small sample and only one saline bag volume tested.

\section{A Comparison of Survival Blankets in Cool Ambient Temperature}

Introduction.-Hypothermia is often cited as the second most common cause of wilderness mortality, and no studies were found comparing efficacy of hypothermia prevention systems or survival blankets.

Methods.-Five 0.5-gal number 7 plastic containers were filled with $108^{\circ} \mathrm{F}$ water and wrapped in a single layer Army combat uniform (ACU) consisting of a polyester t-shirt under layer and polyester rip stop outer layer material around the entire container. The container and ACU wrap was placed in a mylar blanket, Heatsheets ${ }^{\circledR}$ bivy, Blizzard ${ }^{\circledR}$ bivy, Goretex bivy, or no insulator (control) and subjected to ambient temperature for 10 hours ranging from $46.5^{\circ} \mathrm{F}$ to $52.0^{\circ} \mathrm{F}$. The system was opened every hour, containers were agitated, and water temperature was taken with a Fisher Scientific thermometer.

Results.-Mylar 10 -hour heat loss was $46.2^{\circ} \mathrm{F}$, a loss of $43.0 \%$. Mylar costs $\$ 1.50$, weighs $2 \mathrm{oz}$, and its durability was poor. Heatsheets ${ }^{\circledR} 10$-hour heat loss was $48.1^{\circ} \mathrm{F}$, a loss of $44.5 \%$. Heatsheets ${ }^{\circledR}$ costs $\$ 4.99$, weighs 3.5 oz, and its durability was fair; Blizzard ${ }^{\circledR}$ blanket 10 -hour heat loss was $42.4^{\circ} \mathrm{F}$, a loss of $39.2 \%$. Blizzard ${ }^{\circledR}$ blanket costs $\$ 36.99$, weighs 18.5 $\mathrm{oz}$, and its durability was fair; Goretex 10-hour heat loss was $40.4^{\circ} \mathrm{F}$, a loss of $37.4 \%$. Goretex costs $\$ 85.50$, and weighs 39 $\mathrm{oz}$, and its durability was good.

Conclusion.-All survival blankets performed better than the control with Goretex and Blizzard ${ }^{\circledR}$ blankets losing half as much heat as Mylar and Heatsheets ${ }^{\circledR}$ blankets. According to this study, Blizzard ${ }^{\circledR}$ blanket is a superior balance between size, cost, weight, durability, and efficacy.

Andrew Beeghly, DO, FAWM, Capt. USA MC Michael Caudell, MD, FACEP, FAWM Augusta, GA, USA

\section{Inflammatory Markers in Fine Needle Pulmonary Aspirate in Cases of High Altitude Pulmonary Edema}

Background.-The etiopathology of high altitude pulmonary edema (HAPE) is still not fully understood. There has been evidence of inflammation documented in cases of HAPE. If inflammation is even partially responsible for the pathophysiology of HAPE, then an understanding of its role and the type and temporal profile of the inflammatory response would be valuable in the management of HAPE and in the search for better therapies for the condition.

Objective.-This study was taken up to evaluate and characterize the inflammatory response in High Altitude Pulmonary Edema (HAPE) by quantization of the cytokine/chemokines in 